\title{
Corporate identity management and employee brand support: enhancing marketisation in higher education sector
}

\begin{abstract}
Marketing literature has recognized Corporate Identity Management (CIM) in higher education sector as an important area of research. Moreover, current research trend within the continuum of CIM has indicated some ambiguities surrounding corporate identity in higher education. In fact, there is paucity of empirical studies on corporate identity from a higher education perspective. Consequently, the objective of this study is to examine the relationships between university's CIM and employee brand support as well as its relevant causal mechanisms in the higher education sector in Malaysia. The study employed a survey (472) with Malaysian university staff as respondents to test the research hypotheses and the proposed conceptual model. Findings of the study indicated that the Malaysian university staff has some external validity in exploring CIM and employee brand support. The results also demonstrated that the CIM in universities should be merged with strategic communication. Finally, this study provides a better corporate identity management to policy makers, regulators, managers and government in the higher education sector. For example, institutions can inculcate employee brand support in their academic staff to ensure corporate identity management moves in the right direction.
\end{abstract}

Keyword: Corporate identity management; Employee brand support; Image; Visual identity; Higher education 